\title{
Electrospun Copper(II)oxide Fibers as Highly Sensitive and Selective Sensor for Hydrogen Sulfide Utilizing Percolation Effects
}

\author{
Jörg Hennemann ${ }^{1}$, Tilman Sauerwald ${ }^{1,2}$, Thorsten Wagner ${ }^{3}$, Claus-Dieter Kohl', \\ Julia Dräger ${ }^{4}$, Stefanie Russ ${ }^{4}$ \\ ${ }^{1}$ Institute of Applied Physics, Justus Liebig University Giessen, 35392 Giessen, Germany, \\ Joerg.Hennemann@ap.physik.uni-giessen.de \\ ${ }^{2}$ Laboratory of Measurement Technology, Saarland University, 66123 Saarbrücken, Germany \\ ${ }^{3}$ Faculty of Science, Department of Chemistry, University of Paderborn, 33098 Paderborn, Germany \\ ${ }^{4}$ Institut für Theoretische Physik, Freie Universität Berlin, 14195 Berlin, Germany
}

\begin{abstract}
:
We propose a novel sensor for the detection of hydrogen sulfide $\left(\mathrm{H}_{2} \mathrm{~S}\right)$ using a network of electrospun copper(II)oxide (CuO) fibers. The Sensor is very sensitive to $\mathrm{H}_{2} \mathrm{~S}$ with a detection limit below $0.1 \mathrm{ppm}$ and exhibits no response to reducing gases like carbon monoxide, hydrogen, methane or ammonia. This selectivity to $\mathrm{H}_{2} \mathrm{~S}$ is advantageous in highly contaminated gas samples e.g. in biogas reactors. These properties are due to an unique sensor mechanism based on a reversible phase transition of p-type $\mathrm{CuO}$ to degenerated p-type copper sulfide (CuS) in the vicinity of the surface. At a temperature of $160^{\circ} \mathrm{C}$ the sensor shows a steep increase of conductance after a time span $t_{c}$, which depends on the offered $\mathrm{H}_{2} \mathrm{~S}$ concentration. We investigated this mechanism by using a $\mathrm{CuO}$ thin film as a model sensor and interpret the result in a framework of percolation theory. For regeneration the sensor has to be heated up to $350^{\circ} \mathrm{C}$ to convert the CuS back into $\mathrm{CuO}$.
\end{abstract}

Key words: copper(II)oxide, hydrogen sulfide, sensor, sensitive, selective, and percolation

\section{Introduction}

In the last few years the production of renewable energies has considerably increased. An important role in this new energy concept plays biogas generation by anaerobic digestion of e.g. sewage or crop residues. Nevertheless unwanted gases like hydrogen sulfide $\left(\mathrm{H}_{2} \mathrm{~S}\right)$ are formed in this process, too. Hydrogen sulfide leads to corrosion of metal parts of the plant, reduces the stability of engine oil in biogas motors and is harmful to human health $[1,2]$. Only $30 \mathrm{ppm}$ hydrogen sulfide can already lead to heavy disorder of the central nervous system [3]. Therefore, the international occupational exposure limit values are in the range of 1-10 ppm [4]. Therefore, monitoring of $\mathrm{H}_{2} \mathrm{~S}$ is an important issue for save operation and protection of the plant and the operating personnel.

Since the early nineties it is well known that an addition of copper oxide to the polycrystalline tin oxide $\left(\mathrm{SnO}_{2}\right)$ layer of a semiconducting gas sensor increases markedly its sensitivity to $\mathrm{H}_{2} \mathrm{~S}$ [5]. However, $\mathrm{SnO}_{2}$ is prone to poisoning by $\mathrm{H}_{2} \mathrm{~S}$ and shows also (high) sensitivity to various other gases $[6,7]$.
An alternative to the described sensor concept is the usage of pure copper(II)oxide (CuO) as sensor material. It shows a high sensitivity to $\mathrm{H}_{2} \mathrm{~S}$ and only a small response to other gases like e.g. methane and ammonia. Ramgir [8] described in his work two different reaction mechanisms on a microcrystalline $\mathrm{CuO}$ thin film at room temperature. At low concentrations the exposure to $\mathrm{H}_{2} \mathrm{~S}$ leads to an increase of resistivity caused by a surface reaction. At higher concentrations he observed a decrease of resistivity, which is due to a phase transition of semiconducting $\mathrm{CuO}$ to metallic conducting CuS $[9,10]$. In a paper of Chen $\mathrm{CuO}$ is investigated at $160^{\circ} \mathrm{C}$. He observed a change of resistance at high $\mathrm{H}_{2} \mathrm{~S}$ concentrations over several orders of magnitude [11].

In this work we present a new sensor concept. We use electrospun $\mathrm{CuO}$ nanofibers at $160^{\circ} \mathrm{C}$ for the detection of $\mathrm{H}_{2} \mathrm{~S}$ with sensitivity to below $100 \mathrm{ppb}$. The dynamic range amounts to over five orders of magnitude. After a time span $t_{c}$ depending on the offered $\mathrm{H}_{2} \mathrm{~S}$ concentration the conductance makes a steep increase, which can be described by a power law with a critical exponent $\mu$. We found a value of 2.04 between 
the two values that one expects for percolation systems of $2 D \quad(\mu \approx 1.31)$ and $3 D \quad(\mu \approx 2.07)$, respectively. This should be expected for the investigated nanofibers that can be considered as intermediate between the two special dimensions. In this context, it is of special interest that measurements on 2D $\mathrm{CuO}$ thin films [12] show a $\mu$ of 1.28 which is in good accordance to the critical exponent of a pure 2D system. In the state of high conductance the sensor can be refreshed at $350^{\circ} \mathrm{C}$.

This threshold type behaviour (digital signal) allows us to use simple readout electronics. After the switching of conductance the temperature can be raised to $350^{\circ} \mathrm{C}$ for getting the initial state back. So the heat pulses can serve as signal to measure the gas concentration for a certain time.

\section{Preparation}

The copper(II)oxide nanofibers were produced by using a standard electrospinning setup. A solution of poly vinyl butyrate (PVB) and copper nitrate $\mathrm{Cu}\left(\mathrm{NO}_{3}\right)_{2}$ in ethanol (PVB:Cu=1:1) was spun on a metal rack to get a nanofiber network pad. During this process an electric field of $25 \mathrm{kV}$ and an electrode gap of roughly $20 \mathrm{~cm}$ was used (for more details see e.g. [13]).

For electrical readout and heating of the fibers we applied a piece of the polymer nanofibers pad with $\mathrm{Cu}\left(\mathrm{NO}_{3}\right)_{2}$ salt addition on a commercial sensor substrate from UST $\mathrm{GmbH}$. We used a $3 \mathrm{~mm} \times 3 \mathrm{~mm}$ alumina gas sensor substrate with platinum interdigital electrodes and built-in heater (see Fig. 1).

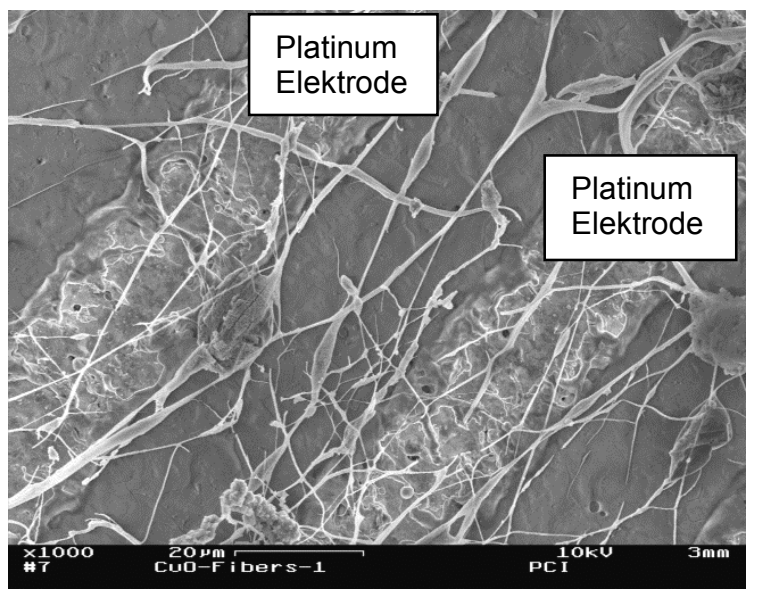

Fig. 1. CuO nanofibers deposited on an UST alumina substrate with IDS platinum electrodes crossing under $45^{\circ}$.

After successive cleaning of the substrates in acetone, isopropyl and distilled water for a few seconds and 5 minutes drying at $600^{\circ} \mathrm{C}$, a drop of distilled water was applied to the substrate. So we attained a better connection with the fibers. Afterwards the substrate was heated up again to $600^{\circ} \mathrm{C}$ within 30 minutes. At this temperature the fibers were calcinated for $24 \mathrm{~h}$ in ambient air to convert the $\mathrm{Cu}\left(\mathrm{NO}_{3}\right)_{2}$ to $\mathrm{CuO}$ [14] and remove the polymer. In the last step the fibers cooled down to room temperature during 30 minutes. The mean diameter of the fibers amounts to $(483 \pm 143) \mathrm{nm}$.

\section{Experimental Settings}

To provide a well-defined gas flow during the gas measurements standard mass flow controllers were used. We used a basic gas flow of synthetic air with $30 \%$ relative humidity and added the test gases to the main stream. The heater of the sensor and the electrical readout of the fibers were controlled by custombuilt electronics. The data were recorded on a PC by a Lab View program. For the measurement we used electrical pulses of $1 \mathrm{~V}$ for $100 \mathrm{~ms}$ each second to suppress electromigration effects. The sensor was operated in a two temperature mode. At the low temperature $\left(160^{\circ} \mathrm{C}\right)$ the gas measurements were performed and at the high temperature $\left(350^{\circ} \mathrm{C}\right)$ the fibers were regenerated [8].

\section{Gas Measurements}

The fiber network was exposed to $5 \mathrm{ppm} \mathrm{H}_{2} \mathrm{~S}$ at low temperature mode. When the exposure has been started at first the conductance has been found decreasing. However, after 54 seconds a slightly steep increase of the conductance over five orders of magnitude occurs (Fig. 2).

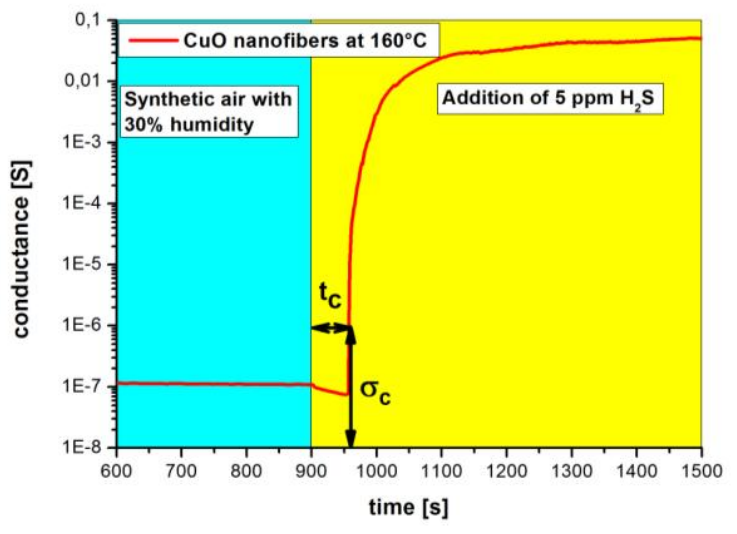

Fig. 2. Conductance change during a continuous $\mathrm{H}_{2} \mathrm{~S}$ exposure of $5 \mathrm{ppm}$, where $t_{c}$ is the time span of the defined switching point $\sigma_{c}$ at $10^{-6} \mathrm{~S}$.

We define a critical time span $t_{c}$ as the interval between the start of the gas exposure and the time, when the critical conductance $\sigma_{c}$ equals $10^{-6} \mathrm{~S}$. After exposure to various concentrations of $\mathrm{H}_{2} \mathrm{~S}$ the fibers show a reciprocal dependency between the offered concentration and the critical time span $t_{c}$. Thereby the fibers were always annealed at $350^{\circ} \mathrm{C}$ prior to each 
measurement in the absence of $\mathrm{H}_{2} \mathrm{~S}$. Then we offered some other reducing gases to the fibers for $1800 \mathrm{~s}$, too. But for them no switching could be observed (Table 1).

Tab. 1: $t_{c}$ for different gases and concentrations

\begin{tabular}{|c|c|c|}
\hline gas & concentration & $\begin{array}{l}\text { Time until } \\
\text { switching }\end{array}$ \\
\hline $\mathrm{H}_{2} \mathrm{~S}$ & $0.1 \mathrm{ppm}$ & $2144 \mathrm{~s}$ \\
\hline $\mathrm{H}_{2} \mathrm{~S}$ & $0.5 \mathrm{ppm}$ & $481 \mathrm{~s}$ \\
\hline $\mathrm{H}_{2} \mathrm{~S}$ & 1 ppm & $234 \mathrm{~s}$ \\
\hline $\mathrm{H}_{2} \mathrm{~S}$ & $2 \mathrm{ppm}$ & $88 \mathrm{~s}$ \\
\hline $\mathrm{H}_{2} \mathrm{~S}$ & 5 ppm & $57 \mathrm{~s}$ \\
\hline Methane & 10000 ppm & No switching \\
\hline \multirow{2}{*}{$\begin{array}{c}\text { Carbon } \\
\text { monoxide }\end{array}$} & 100 ppm & No switching \\
\hline & $20 \mathrm{ppm}$ & No switching \\
\hline Ammonia & $300 \mathrm{ppm}$ & No switching \\
\hline
\end{tabular}

\section{Regeneration}

During regeneration bake out at $350^{\circ} \mathrm{C}$ the conductance of the fibers decreases within five minutes. Thereafter the conductance remains at a constant level. When the fibers were tempered for 30 minutes without $\mathrm{H}_{2} \mathrm{~S}$ an EDX analysis showed that the sulfur had been completely removed (Fig. 3). The appearance of platinum and aluminum peaks are due to the sensor substrate.

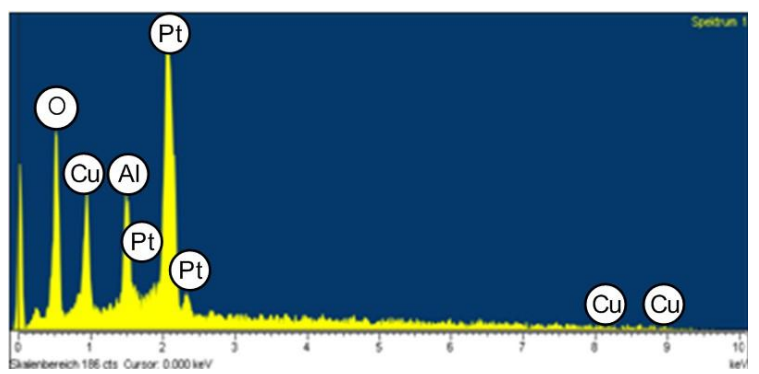

Fig. 3. EDX analysis of the tempered fibers after 30 minutes at $350^{\circ} \mathrm{C}$.

\section{Data Analysis}

An analysis of the steep conductance increase of the $5 \mathrm{ppm}$ measurement shows two different regimes that we interpret as a transition between two different power laws. In figure 4, to discover the exponents of these regimes, we plot $\sigma-\sigma_{\mathrm{c}}$ versus $\mathrm{t}-\mathrm{t}_{\mathrm{c}}$ in a double-logarithmic plot, i.e. we start the presentation at the switching time. A fit of the critical exponent of the first regime (green line) shows a behavior as [15]

$\sigma \sim\left(t-t_{c}\right)^{\mu}$

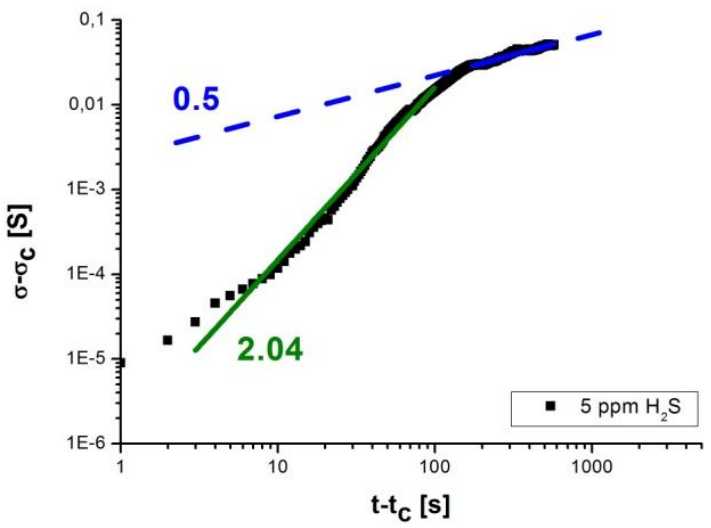

Fig. 4. Measurement of the $5 \mathrm{ppm}$ concentration plotted as a function of $t-t_{c}$ and $\sigma-\sigma_{c}$ in a double logarithmic scale.

with $\mu \approx 2.04$. This strong increase is followed by much smoother increase with an exponent of about 0.5 (blue line).

\section{Discussion}

When $\mathrm{CuO}$ is exposed to $\mathrm{H}_{2} \mathrm{~S}$ at low temperatures (e.g. $160^{\circ} \mathrm{C}$ ) it undergoes a successive phase transformation by generating highly conductive copper sulfide (CuS) clusters [11]. We assume that as long as the CuS clusters are disjunct they do not contribute significantly to the conductance. If the fraction $p$ of surface covered by CuS clusters in relation to the entire surface of a fiber/film exceeds a critical value $p_{c}$, percolating pathways are formed. The conductance is almost immediately dominated by the CuS pathways. The influence of the confined geometry of the disordered CuS structure on the conductivity can be described by percolation theory [15].

The assumption that the CuS density after the formation of the percolating pathways (which takes place at the switching time $t_{c}$ increases proportional to the time $t,\left(t-t_{c}\right) \sim\left(p-p_{c}\right)$, leads to the following prediction (see also [12]) for the increase of the conductivity

$\sigma_{D C} \sim\left(t-t_{c}\right)^{\mu}$

with $\mu=v\left(d_{w}-2\right)+v\left(d-d_{f}\right)$. Here the anomalous diffusion exponent $d_{w}$, the fractal dimension $d_{f}$ and the exponent $v$ are universal for percolation systems leading to $\mu=1.31$ in $d=2$ and $\mu=2.07$ in $d=3$. Recently, we have proven for copper oxide thin films that the conductance characteristics after the switching time $t_{c}$ follows a power law with the exponent $\mu=1.28$ predicted by percolation theory for $2 \mathrm{D}$ disordered systems. This shows that the CuS network can be seen as a constantly growing, fractal network on a 2dimensional plane. Figure 4 shows that for the fiber network the increase of conductance above the percolation threshold is steeper than 
in the 2D system [12] with an exponent of $\mu=2.04$. The complex CuS-structure growing on the fiber network seems to feature 3D effects. After a long exposure to $\mathrm{H}_{2} \mathrm{~S}$ the surface is completely covered by CuS clusters. At this stage the increase of conductance is dominated by the growth of the film thickness. Considering a growth mechanism dominated by bulk diffusion the thickness and thus the conductance of CuS films should increase proportional to $\mathrm{t}^{0.5}$, which is in good accordance to our experimental data (fig. 4 inset blue line). The EDX analysis verifies that during the annealing process at high temperature the CuS is reoxidized to $\mathrm{CuO}$. The other test gases do not cause switching.

\section{Conclusion}

The sensor operation will involve a change between a low temperature state at $160^{\circ} \mathrm{C}$ and a high temperature state at $350^{\circ} \mathrm{C}$. Here we are using the time span $t_{c}$ describing the formation of a percolation path in the low temperature state as sensor signal. The fiber structure shows a high sensitivity above 100ppb over 5 orders of magnitude to $\mathrm{H}_{2} \mathrm{~S}$. The sensor does not show any cross sensitivities to the other test gases. The critical exponent of the fibers is steeper than expected for a pure 2-dimensional percolation system. This nearly digital signal helps to simplify measurement electronics.

\section{Acknowledgements}

We thank Prof. Dr. Andreas Greiner and Michael Bognitzki for the preparation of the nanofibers.

We are gratefully to the DFG for financial support of our research.

\section{References}

[1] D. Schieder, P. Quicker, R. Schneider, H. Winter, S. Prechtl, M. Faulstich, Microbiological removal of hydrogen sulfide from biogas by means of a separate biofilter system: experience with technical operation, Water Science and Technology Vol 48 No 4, 209-212 (2013)

[2] S. Pipatmanomai, S. Kaewluan, T. Vitidsant, Economic assessment of biogas-to-electricity generation system with $\mathrm{H}_{2} \mathrm{~S}$ removal by activated carbon in small pig farms, Applied Energy 86, 669-674 (2009); doi: 10.1016/j.apenergy.2008.07. 007

[3] IFA, GESTIS Substance Database, keyword: hydrogensulfide, accessed 2012-03-25 ; http://gestis-en.itrust.de/nxt/gateway.dll?f= templates\$fn=default.htm\$vid=gestiseng:sdbeng

[4] IFA, GESTIS International Limit Values, keyword: hydrogen sulphide, accessed 2012-03-25; http://limitvalue.ifa.dguv.de
[5] J. Tamaki, T. Maekawa, N. Miura, N. Yamazoe, $\mathrm{CuO}-\mathrm{SnO}_{2}$ element for highly sensitive and selective detection of $\mathrm{H}_{2} \mathrm{~S}$, Sensors and Actuators B 9, 197-203 (1992); doi: 10.1016/09254005(92)80216-K

[6] D. Kohl, J Kelleter, H. Petig, Detection of Fires by Gas Sensors, Sensors Update 9, 161-223 (2001); doi: 10.1002/1616-8984(200105)9:1<161::AIDSEUP161>3.0.CO;2-A

[7] D. Kohl, Function and applications of gas sensors, Journal of Physics D 34, 125-149 (2001); doi: 10.1088/0022-3727/34/19/201

[8] N. S. Ramgir, S. Kailasa Ganapathi, M. Kaur, N. Datta, K. P. Muthe, D. K. Aswal, S. K. Gupta, J. V. Yakhmi, Sub-ppm $\mathrm{H}_{2} \mathrm{~S}$ sensing at room temperature using $\mathrm{CuO}$ thin films, Sensors and Actuators B 151, 90-96 (2010); doi: 10.1016/j.snb.2010.09.043

[9] Y. K. Jeong, G. M. Choi, Nonstoichiometry and electrical conduction of $\mathrm{CuO}$, Journal of Physics and Chemistry of Solids 57, 81-84 (1996); doi: 10.1016/0022-3697(95)00130-1

[10] Y. B. He, A. Polity, I. Österreicher, D. Pfisterer, R. Gregor, B. K. Meyer, M. Hardt, Hall effect and surface characterization of $\mathrm{Cu}_{2} \mathrm{~S}$ and CuS films deposited by RF reactive sputtering, Physica $B$, 308-310 (2001); doi: 10.1016/S09214526(01)00851-1

[11] J. Chen, K. Wang, L. Hartman, W. Zhou, $\mathrm{H}_{2} \mathrm{~S}$ Detection by Vertically Aligned CuO Nanowire Array Sensors, The Journal of Physical Chemistry C, 16017-16021 (2008); doi: 10.1021/jp805919t

[12] J. Hennemann, T. Sauerwald, J. Dräger, S. Russ, D. Kohl, in preparation

[13] M. Bognitzki, W. Czado, T. Frese, A. Schaper, M. Hellwig, M. Steinhart, A. Greiner, J. H. Wendorff, Nanostructured Fibers via Electrospinning, Advanced Materials 13, 70-72 (2001); doi: 10.1002/1521-4095(200101)13:1<70::AIDADMA70>3.0.CO;2-H

[14] L. Wan, X. Cui, H. Chen, J. Shi, Synthesis of ordered mesoporous $\mathrm{CuO} / \mathrm{CeO} 2$ composite via co-nanocasting replication method and its improved reactivity towards hydrogen, Materials Letters 64, 1379-1382 (2010); doi: 10.1016/j.matlet.2010.03.025

[15] S. Havlin, D. Ben-Avraham, Diffusion in disordered media, Advances in Physics 36, 695798 (1987); doi: 10.1080/00018738700101072 